\title{
Chronic thalamic stimulation improves tremor and levodopa induced dyskinesias in Parkinson's disease
}

Dominique Caparros-Lefebvre, Serge Blond, Patrick Vermersch, Nathalie Pécheux, Jean-Daniel Guieu, Henri Petit

\begin{abstract}
Chronic thalamic stimulation was performed in 10 Parkinsonian patients with disabling tremor and poor response to drug therapy. During the stereotactic procedure, an electrode was introduced in the ventralis intermediate nucleus of the thalamus. Test stimulation was performed during the intra-operative procedure and a few days after surgery using an external stimulator. When tremor was obviously reduced by thalamic stimulation, an internal stimulator was implanted under the clavicle. Tremor was initially suppressed in all cases and reappeared whenever stimulation was stopped. Patients were followed for 22 to 34 months. Tremor was controlled in eight cases but reappeared after three months in two cases. Levodopa induced dyskinesias were observed before electrode implantation in 5 cases. They consisted of peak-dose choreic or ballistic dyskinesias in 4 cases and biphasic dystonic dyskinesias in 3 cases. Peak-dose dyskinesias were greatly improved or suppressed in all cases. Biphasic dyskinesias were improved in 2 cases. Thalamic stimulation was well tolerated. Mild dystonic hand posture related to the deep brain stimulation was observed in one case. No neuropsychological sideeffects were noted. Thalamic stimulation could prove to be an adequate treatment for resistent tremor and levodopa induced dyskinesias.
\end{abstract}

(F Neurol Neurosurg Psychiatry 1993;56:268-273)

Department of Neurology, CHRU Lille, France

D Caparros-Lefebvre

$P$ Vermersch

N Pècheux

H Petit

Department of Neurosurgery, CHRU Lille, France

$S$ Blond

Department of Neurophysiology, CHRU Lille, France

J-D Guieu

Correspondence to:

Dr Caparros-Lefebvre,

Clinique Neurologique ( $\mathrm{Pr}$

$H$ Petit), CHRU IILE,

59037 LILLE Cèdex,

France

Received 7 August 1991

and in final revised form

3 June 1992.

Accepted 19 June 1992 of thalamotomy has been re-evaluated since 1978, despite the risk of neurological damage. ${ }^{6}$ It was suggested that thalamic stimulation could be a safer technique. ${ }^{7}$ Brice and McLellan ${ }^{8}$ and Andy ${ }^{9}$ reported a decrease or a suppression of various kinds of tremor by transient stimulation performed during sterotactic thalamotomy. Benabid et al ${ }^{10}$ implanted a stereotactic high frequency stimulation device in the VIM nucleus to control Parkinsonian tremor, and obtained good results. The favourable effect of chronic thalamic stimulation seems to be maintained long term. ${ }^{112}$ However, the effect of thalamic stimulation on levodopa induced dyskinesias has never been evaluated. In this study, the results of chronic VIM stimulation performed in 10 Parkinsonian patients are reported.

\section{Material and methods}

Ten patients w ith idiopathic Parkinson's disease (PD) gave their informed consent for thalamic stimulation. They were selected on the basis of prominent tremor and poor response of tremor to anti-Parkinsonian drugs: levodopa, bromocriptine, anticholinergic agents. Despite low levodopa daily doses in some patients, thalamic stimulation was proposed especially where severe levodopa induced dyskinesias occurred (patients 4 and 8). Patients with a mild akineto-hypertonic syndrome also received low doses of levodopa but their tremor responded poorly to the test treatment $(250 \mathrm{mg}+$ decarboxylase inhibitor). In all cases, tremor was severely disabling during at least 5 hours of the day.

Under general anaesthesia, the patients were placed in a Talairach stereotactic frame. The anterior commissure (AC)-posterior commissure (PC) line was defined by double contrast ventriculography. The Sceratti arc adaptation to the instrument allowed introduction of a. $1.3 \mathrm{~mm}$ in diameter, $3.5 \mathrm{~mm}$ long monopolar electrode with a volume of $4 \mathrm{~mm}^{3}$ volume (MEDTRONIC) through the frontal lobe from an oblique angle in sagittal and coronal planes. The electrode was placed with its control stylet in the VIM (target) stereotactically, $6 \mathrm{~mm}$ in front of the PC, 1 $\mathrm{mm}$ above bicommissural line, and $15 \mathrm{~mm}$ from the anatomical midline. A screw made of pure titanium was used to secure the electrode in a $2.5 \mathrm{~mm}$ burr hole. The electrode was initially connected to a percutaneous extension for test stimulation during surgery. At high frequency $(100 \mathrm{~Hz})$, paraesthesiae were noticed and tremor was blocked. Test 
Table 1 Main clinical features. For each patient, age, disease duration, Hoehm and Yahr stage, response to drug therapy, levodopa daily dose, effect on dyskinesias and follow up are given.

\begin{tabular}{lllllllll}
\hline Patient & $\begin{array}{l}\text { Age } \\
\text { years }\end{array}$ & $\begin{array}{l}\text { Disease } \\
\text { duration } \\
\text { (years) }\end{array}$ & $\begin{array}{l}\text { Hoehn } \\
\text { and Yahr } \\
\text { stage }\end{array}$ & $\begin{array}{l}\text { Tremor } \\
\text { response } \\
\text { to Levodopa }\end{array}$ & $\begin{array}{l}\text { Levodopa } \\
\text { daily } \\
\text { before }\end{array}$ & $\begin{array}{l}\text { Levodopa } \\
\text { dose } \\
\text { after }\end{array}$ & $\begin{array}{l}\text { Effect } \\
\text { on } \\
\text { Dyskinesias }\end{array}$ & $\begin{array}{l}\text { Follow-up } \\
\text { in } \\
\text { months }\end{array}$ \\
\hline 1 & 60 & 9 & III & transient & 300 & 300 & PD:suppressed & 34 \\
2 & 68 & 8 & III & 0 & 600 & 600 & PD:suppressed & 30 \\
$3($ T) & 57 & 15 & IV & 0 & 300 & 300 & OED:unchanged & 29 \\
4 & 74 & 10 & IV & moderate & 550 & 550 & PD + OED:improved & 28 \\
5 & 62 & 6 & II & mild & 300 & 300 & - & 28 \\
6 & 59 & 9 & III & mild & 300 & 300 & - & 28 \\
7 (T) & 58 & 9 & III & mild & 400 & 400 & PD + OED:suppressed & 25 \\
8 (T) & 56 & 24 & III & moderate & 300 & 300 & PD & 24 \\
9 & 68 & 4 & II & 0 & 300 & 300 & - & 22 \\
10 & 63 & 7 & II & mild & 300 & 300 & - & 27 \\
MEANS & $62 \cdot 5$ & 10.4 & $2 \cdot 9$ & - & 365 & 365 & - & \\
\hline
\end{tabular}

$(T)=$ contralateral thalamotomy performed before thalamic stimulation

$\mathrm{PD}=$ peak dose dyskinesia

$\mathrm{OED}=$ onset and end of dose dyskinesias

stimulation was continued for a few days during the postoperative period. If tremor control was satisfactory, a neuro-pacemaker ITREL I (MEDTRONIC) was implanted under the clavicle and connected to the electrode. For all patients, parameters of stimulation programmed by telemetry were: intensity -1 to 3.75 volts (mean: 2.025 ); pulse width-60 to 210 microseconds (mean: 150); frequency: $130 \mathrm{Hertz}$. When stimulation was started, transient paraesthesiae of the contralateral hand and lips corner were evoked whereas tremor was suppressed. 4 patients (cases $2,3,7,9$ ) were permanently stimulated day and night. Stimulation was continued all day and stopped at night in 6 patients.

Electrode coordinates were defined with great accuracy at the end of the surgical procedure, in the stereotactic space. The mean (SD) coordinates of the electrode active tip were: $6(1.8) \mathrm{mm}$ in front of the PC $[23.6 \%$ $(0.8)$ of AC-PC length], $13.8(1.3) \mathrm{mm}$ from the anatomical midline and at the level of bicommissural line. In case 8 (in which the levodopa induced dyskinesias were suppressed by stimulation), the active tip was located at $8 \mathrm{~mm}$ in front of the PC $(35 \%$ of AC-PC length), $14.5 \mathrm{~mm}$ lateral to the medial plane.

Tremor was assessed according to the Unified Parkinson's Disease Rating Scale (UPDRS) ${ }^{13}$ before and after thalamic stimulation on videotape recordings. Videotapes were analysed by three neurologists who quantified rest and postural tremor in the upper limbs, rest tremor in the lower limbs, and axial tremor.

Dyskinesias were rated on a four-point scale $(0=$ nil, $1=$ mild, $2=$ moderate, 3 $=$ severe) before neurosurgery and after electrode implantation with and without stimulation.

In each case, tremor was evaluated at rest by surface EMG and accelerometer recordings before and after thalamic stimulation on the same limb. EMG activities were recorded with pairs of surface electrodes placed 6 centimetres apart over the flexor and extensor radialis. An accelerometer (BLA 2 Dynamics) was fixed over the dorsal face of the first phalanx of the second finger. Frequency analyses of the taped signals were performed either on
OTE BFA 1264 or Nicolet PII recorder. After electrode implantation, surface EMG and accelerometer recordings were performed, with and without stimulation to prove tremor suppression and to define the delay before tremor control after onset of stimulation and the delay before reappearance of tremor after stimulation was discontinued.

Cognition was assessed pre and post-operatively in 8 patients (cases $1,2,4,5,6,8,9$, 10). Frontal lobe function, memory, language and praxis skills were tested with and without stimulation. The tests and results have been described previously. ${ }^{14}$

\section{Results}

\section{1) PATIENTS WITHOUT LEVODOPA INDUCED} DYSKINESIAS (table 1)

In 5 patients (cases $5,6,7,9,10$ ), Parkinsonian symptoms were not associated with abnormal involuntary movements (AIMs). The average age was 62 years (58-68), and the average disease duration was 5 years (4-9). Contralateral stereotactic thalamotomy had been performed one year before stimulation in one case. Hoehn and Yahr stage was II in 3 cases and III in 2 cases. Tremor was suppressed by thalamic stimulation in 4 cases. In the last patient (with previous thalamotomy), neither right thalamic lesion nor left thalamic stimulation controlled tremor which was only moderately improved.

\section{2) PATIENTS WITH LEVODOPA INDUCED}

\section{DYSKINESIAS}

In 5 cases, both Parkinsonian tremor and levodopa induced dyskinesias were observed (table 1). The clinical features and effects of thalamic stimulation are described in more detail in these cases.

Case 1: This right handed patient was affected in 1973 by postural tremor which remained isolated for $\mathbf{8}$ years. Akineto-hypertonic syndrome then appeared in the right arm. Rest and postural tremor were prominent, and were not improved by increasing the daily dose of levodopa. Thalamic stimulation of the left VIM nucleus was performed in May 1989. Spontaneous and evoked thalamic activities were recorded during the stereotactic procedure only in this patient. Tremor was 
Figure 1 Tremor frequency analysis in case 1. Tremor frequency was analysed before and after thalamic electrode implantation and also with and without thalamic stimulation. Spectral analysis was performed using EMG records on wrist flexor and extensor muscles of the right arm. A) before surgery, B) after electrode implantation without stimulation, $C$ ) during thalamic

stimulation no rhythmic activity was recorded.

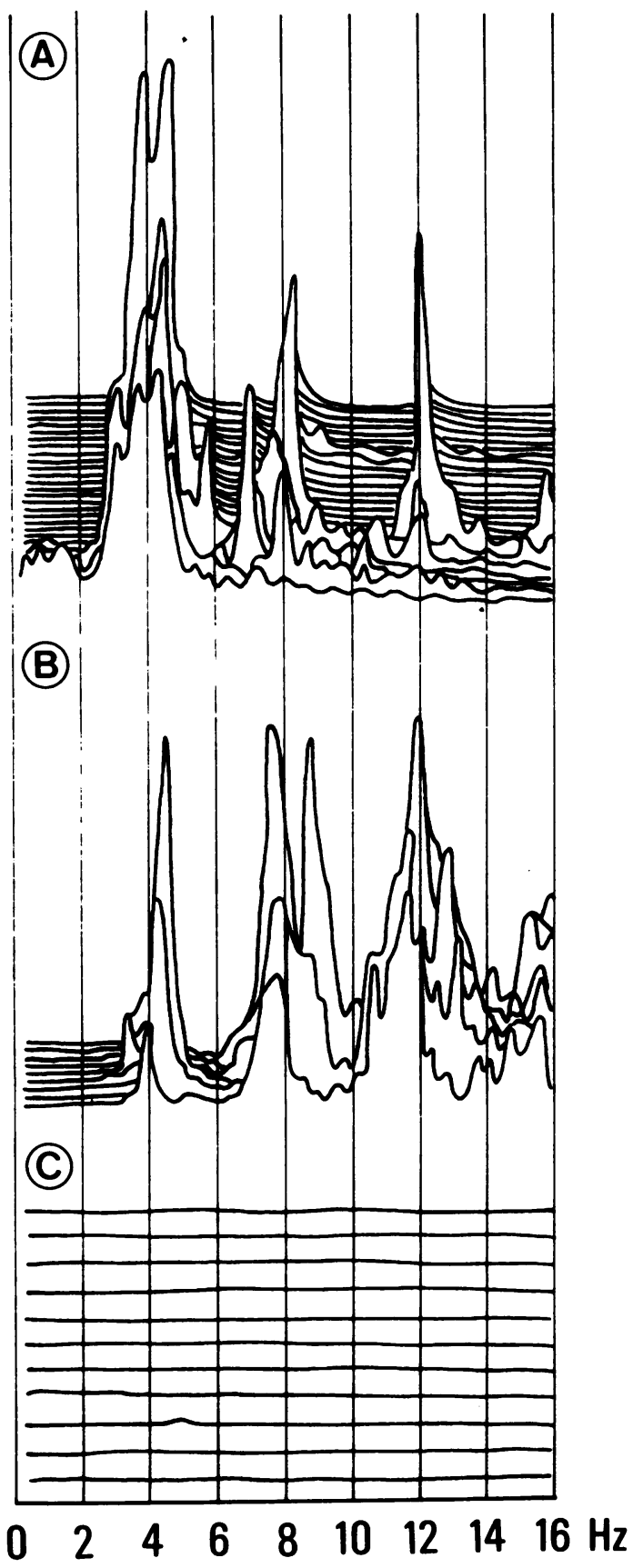

completely controlled on right limbs during stimulation. Tremor frequency analysis (from wrist flexor and extensor muscles of right arm EMG records) showed a dominant peak at 4 hertz $(\mathrm{Hz})$ and fundamental frequency harmonics at 8 and $12 \mathrm{~Hz}$ before surgery. The 4 $\mathrm{Hz}$ peak was reduced after deep brain electrode implantation. After stimulation was started, all rhythmic activities disappeared (fig 1). Choreic dyskinesias of the right arm and face disappeared after neurosurgery although the daily dose of levodopa remained the same.

Case 2: This patient complained of rest tremor in the dominant right leg from 1981. Prominent tremor was observed in the right limbs and face when he was admitted in September 1989. Interdose dyskinesias were located in the right arm. Right limb and facial tremor was suppressed by left VIM stimulation, which was well tolerated. When stimulation was stopped a coarse tremor reappeared after ten to twenty seconds. Interdose dyskinesias were suppressed by thalamic stimulation.

Case 3: This right handed patient had rest and postural tremor in the left limbs from 1975. Parkinsonian signs were marked when she was first examined in April 1988, before stereotactic thalamotomy. She was depressed, dependant on aid for all daily activities, and almost confined to a wheelchair. Axial signs including dysarthria and postural symptoms with falls were marked. She also complained of biphasic dystonic dyskinesias of both feet. Left limb tremor was alleviated by thalamotomy of the right ventrolateral (VL) nucleus. Nevertheless, moderate tremor of the left limbs reappeared a few months later. Stimulation of the left VIM nucleus for contralateral tremor control was performed 17 months later. Right limb tremor was initially suppressed. Moderate tremor reappeared after 8 months in the right limbs under stimulation. Biphasic dyskinesias remained unchanged, mild in the right foot and moderate in the left foot. No side-effects were noted.

Case 4: This right handed patient exhibited rest and postural tremor in the left limbs since 1980. AIMs which consisted of dystonic biphasic dyskinesias in the left limbs, choreic interdose dyskinesias in the arms and face, blepharospasm and segmental myoclonus were observed when she was admitted for thalamic stimulation in November 1989. Both tremor and levodopa induced dyskinesias in the left limbs were controlled by right VIM nucleus stimulation. Right limb dyskinesias and blepharospasm were not modified by neurosurgery. When thalamic stimulation was switched on, the delay for tremor control was about 3 seconds on accelerometer records (on the left forefinger). When stimulation was switched off left limb tremor reappeared with the same delay (fig 2). There were no adverse effects.

Case 8: The patient complained of disabling tremor in the dominant right arm in 1966. In 1968 thalamotomy was performed 
and controlled perfectly right limb tremor, but hemiparesis was noted. Disabling left arm tremor was observed in 1976, postural signs with falls appeared in 1983, and dysarthria was noted in 1988. He developed severe interdose dyskinesias in 1984 and mild dystonic dyskinesias in 1987 . He was also affected by prominent lingual tremor. When he was admitted for thalamic stimulation, prominent tremor was seen only in the left limbs without levodopa whereas disabling ballistic dyskinesias were observed on the same side with levodopa. On the right side, no tremor or dyskinesias were observed. Right VIM nucleus stimulation controlled perfectly left limb tremor with no side-effects. Lingual tremor was also controlled by thalamic stimulation. Interdose choreic and ballistic dyskinesias were suppressed during stimulation, although the daily dose of levodopa was not reduced. The ballistic movements reappeared soon after thalamic stimulation were suppressed. Dystonic dyskinesias were suppressed by stimulation.

\section{3) FOLLOW UP}

One to three months after thalamic implantation, a coarse tremor of higher magnitude than before surgery was observed at rest and during movement in 6 cases $(1,2,3,7,8,9)$ whenever stimulation was discontinued. This rebound-effect lasted a few minutes to a few hours, and was so impressive in 4 cases $(2,3$, 7 and 9, with higher stimulation intensity) that stimulation was maintained during the night. But in 2 cases $(2,7)$, after a longer interruption for replacement of the neuropacemaker, the rebound-effect was progressively reduced and disappeared within 2 days.

\section{4) NEUROPSYCHOLOGICAL ASSESSMENT}

The main neuropsychological results have been previously reported. ${ }^{14}$ Intellectual and frontal lobe functions were not damaged by thalamic stimulation. A transient ideo-motor slowing was observed in case 1 . Neither dysarthria nor aphasia appeared after thalamic stimulation. A dysarthria was noted before neurosurgery in 2 cases $(3,8)$, but did not deteriorate after surgery. Neurological examination failed to show motor or sensitive impairment, or neglect, after neurosurgery.

The effect of thalamic stimulation was evaluated in the treatment of disabling rest and postural Parkinsonian tremor. The average age was 62.5 years. The average disease duration was 10.4 years. Levodopa induced dyskinesias affected half of them before surgery. Tremor suppression was obtained in 8 cases. An unexpected favourable effect was observed on dyskinesias.

\section{Discussion}

1) NEUROSURGICAL PROCEDURE

a) Site of stimulation: The transient paraesthesiae evoked every time stimulation was started mainly involved the hand and corner of the lips contralateral to the thalamus stimulated. This seems to indicate that the elec- trode tip was located in the ventro-medial part of VIM according to somatotopic organisation of VIM nucleus. ${ }^{15}$ The VIM nucleus is $2 \mathrm{~mm} / 4.5 \mathrm{~mm} / 4 \mathrm{~mm}$ (length/height/width), according to Schaltenbrand atlas, ${ }^{16}$ with an estimated volume of 36 to $40 \mathrm{~mm}^{3}$. The electrode volume is therefore more than 9 times smaller than VIM volume indicating that the target, the medial part of the VIM, must be accurately defined to achieve satisfactory results. The electrode site may be defined both by deep brain microelectrode recording VIM activities, and intraoperative test stimulation. ${ }^{12}$ In our study, VIM activities records were obtained only for case 1, but intraoperative stimulation was performed in all cases. VIM activity records are not infallible guides to lesions for the relief of tremor, ${ }^{17}$ and the increase in the duration of the operation seemed to us prejudicial to old patients. Finally, intraoperative test stimulation allowed definition of the most appropriate site for the active tip. Moreover, the mean coordinates were similar to those described by Benabid et $a l,{ }^{12}$ although the approach to the thalamus was parasagittal in those studies. In case 8 where AIMs were suppressed by stimulation, the location of the active tip was more anterior: $8 \mathrm{~mm}$ in front of PC, $35 \%$ of AC-PC line length.

b) Stimulation parameters: During the follow up, stimulation parameters were modified. Current intensity was increased in all cases to avoid reappearance of tremor. Despite moderate voltage (3 volts) and adequate pulse width (90 microseconds), dystonic posture of the right hand induced by current diffusion to the internal capsule was observed in case 9. Impulse frequency was limited to $130 \mathrm{~Hz}$ because of technical problems but higher frequency stimulation could provide better control of tremor..$^{12}$

\section{2) EFFECT ON TREMOR}

Tremor was suppressed in 8 of the 10 patients. In the recent series of Benabid et $a l,{ }^{12}$ tremor was suppressed in $67 \%$ and greatly improved in $94 \%$ of Parkinsonian cases but the efficacy of thalamic stimulation appeared to be limited when tremor was axial or prevalent in the proximal part of the limbs. In this study, thalamic stimulation was effective on axial, especially lingual tremor.

In all cases, tremor was reduced without stimulation during 3 to 15 days after the operation but reappeared after that time. This micro-thalamotomy like effect, also reported by Benabid et al ${ }^{11} 12$ might be related to transient oedema after electrode implantation. It was also observed on EMG records and spectral analysis of tremor in case 1 . The amplitude of the low frequency peak was reduced after implantation without stimulation.

The physiopathological explanation for the rebound effect, which was usually observed for a short period after thalamic stimulation is not known. It has not been established whether the effect of stimulation is related to inhibition or stimulation of thalamic neurons but the rebound effect and the similarity 
between thalamotomy and thalamic stimulation suggest that inhibition is probable. ${ }^{12}$

At present, long-term results of thalamic stimulation cannot be evaluated or compared with thalamotomy. In the large series of stereotactic thalamotomy, tremor disappeared in $75-85 \%$ of the cases. ${ }^{18} 19$ The same efficacy may be obtained on tremor with thalamic stimulation but adverse effects appeared reversible and less common.

\section{3) EFFECT ON DYSKINESIAS}

The aim of thalamic stimulation was to relieve contralateral tremor but an obvious and unexpected effect was also obtained on levodopa induced AIMs. The alleviation of AIMs by thalamotomy was controversial ${ }^{2021}$ until Narabayashi ${ }^{22}$ demonstrated that combined lesion of the VIM and ventral oralis (VO) complex, which is located just in front of VIM, could be effective on choreic and ballistic levodopa induced dyskinesias. Indeed, case 8 was not affected by interdose dyskinesias on limbs contralateral to previous left thalamotomy. Benabid, ${ }^{10-12}$ however, did not report improvement of levodopa induced dyskinesias after thalamic stimulation.

Choreic and ballistic movements induced by levodopa may arise from inhibition of the subthalamic nucleus ${ }^{23-25}$ which projects mainly to the substantia nigra and medial pallidum. ${ }^{26}$ Primates with Parkinsonism induced experimentally by $\mathrm{N}$-methyl-4-phenyl-1,2,3,6 tetra-hydropyridine (MPTP) developed dyskinesias after the introduction of levodopa therapy. ${ }^{27}$ The occurrence of AIMS in these primates seems to be related to abnormal underactivity of the medial pallidal segment ${ }^{27}{ }^{28}$ which projects inhibitory outputs to the ventro-lateral nucleus. ${ }^{29}$ The underactivity of inhibitory outputs to the thalamus might induce thalamic disinhibition. Finally, thalamic disinhibition may be the most relevant alteration in the occurrence of different patterns of movement disorders. The destruction by thalamotomy or disruption by electrical stimulation of this area could be effective on levodopa AIMs. Our results seemed consistent with anatomical and physiological studies and also with the results of thalamotomy performed by Narabayashi. ${ }^{22}$ The electrode coordinates could have a prominent role in dyskinesia alleviation. This electrode which is introduced with double obliquity crosses the ventro-lateral nucleus before it reaches VIM nucleus. The dramatic improvement of levodopa induced dyskinesias which was obtained in case 8 may be related to the anterior location of the electrode tip, probably in the ventro-lateral nucleus (or ventral oralis complex).

Paradoxically, it may appear still that levodopa is effective on Parkinsonian symptoms but induces AIMs, whereas thalamic stimulation alleviates both tremor and peak-dose dyskinesias. This may be related to the differential action of levodopa, and thalamic stimulation which may influence both dopaminergic and non-dopaminergic pathways. The thalamic nuclei appeared to be the last relay of complex neuronal loops which finally project to the motor and premotor cortex. ${ }^{23} 30$ Inhibition of this last relay might therefore be effective on both movement disorders: tremor and dyskinesias. Dystonic dyskinesias seemed to be less influenced by thalamic stimulation. If biphasic dyskinesias are also induced by levodopa therapy, their pathogenesis may be different and involve a different dopaminergic receptor subtype, moreover they seem to be due to dysfunction in different topographically organised systems. ${ }^{31}$ It was expected that the daily dose of levodopa could be reduced after surgery, but this was not the case. As peak-dose dyskinesias were improved after thalamic stimulation, the daily dose can be increased without fear of peak-dose dyskinetic side-effects when Parkinsonian signs require it.

This study suggests that thalamic stimulation may be an adequate choice in the treatment of some cases of Parkinsonian tremor such as: 1) When tremor is of high amplitude, severely disabling, prevalent on one side, persistent despite other adequate treatments; 2) When tremor affects the same limbs as levodopa induced dyskinesias; 3) When tremor is associated with speech disorders; 4) When there has been previous contralateral thalamotomy or thalamic stimulation for bilateral parkinsonian tremor; 5) When interdose dyskinesias in young patients are particularly disabling.

Should use of the device become widespread in the future, its cost may be reduced, and this safe technique could be proposed to a greater number of patients.

We thank Professor Warter, CHRU Strasbourg and Professor Arnott, CHRU Lille who committed some patients to our care during this study and we are grateful for Merle Ruberg for the critical review of the manuscript.

1 Hassler R, Riechert T. Indikationen und Lokalisationsmethode der gezieolten Hirnoperationen. Nervenarzt 1954;25:411-7.

2 Albe-Fessard D, Arfel G, Guiot G, Hardy J, Vourc'h G, Hertzog E, Aleonard P, Derome P. Dérivations d'activcérébrales profondes de l'homme. Revue Neurologique 1962;106::89-105

3 Ohye C, Narabayashi H. Physiological study of presumed ventralis intermedius neurons in the human thalamus. $\mathcal{F}$ Neurosurg 1979;50:290-7.

4 Hirai $T$, Miyazaki M, Nakajima $H$, Shibazaki $T$, Ohye C. The correlation between tremor characteristics and the predicted volume of effective lesions in stereotaxic nucleus ventralis intermedius thalamotomy. Brain 1983;106:1001-18.

5 Tasker RR, Siqueira J, Hawrylyshyn P, Organ LW. What happened to VIM thalamotomy for Parkinson's disease? Applied Neurophysiology 1983;46:68-83.

6 Wester K, Hauglie-Hanssen E. Stereotaxic thalamotomyexperiences from levodopa era. $\mathcal{F}$ Neurol Neurosurg
Psychiatry 1990;53:427-30.

7 Blond S, Siegfried J. Thalamic stimulation for the treatment of tremor and other motor movement disorders. Acta Neurochirurgica. Proc 9th Congr Eur Soc Stereotaxis Funct Neurosurg 1991. Acta Neurochirurgica Suppl 1991;52:109-111.

8 Brice J, Mac Lellan L. Suppression of intention tremor by contingent deep brain stimulation. Lancet 1980;2: $1221-2$.

9 Andy DJ. Thalamic stimulation for control of movement disorders. Applied Neurophysiology 1983;46:107-111.

10 Benabid AL, Pollack P, Louveau A, Henry S, De Rougemont J. Combined (thalamotomy and stimulation) stereotaxic surgery of the VIM thalamic nucleus for bilateral Parkinson's disease. Proc Am Soc 作 Neurophysiology 1987;50:344-6.
Neretaxis Montreal. Applied

11 Benabid AL, Pollack P, Hommel M, Gaio JM, De Rougement J, Perret J. Traitement du tremblement 
parkinsonien par stimulation chronique du noyau venparkinsonien par stimulation chronique du noyau ventral intermediaire

12 Benabid AL, Pollack P, Gervason C, Hoffman D, Gao DM, Hommel M, Perret JE, De Rougemont J. Long term suppression of tremor by chronic stimulation of the ventral intermediate thalamic nucleus. Lancet 1991 337:403-6.

13 Fahn S, Elton RL and members of The UPDRS Development Committee. Unified Parkinson's Disease Rating Scale. In: Fahn S, Marsden CD, Calne D, Goldstein M, eds. Recent developments in Parkinson's disease, Vol 2. New Jersey, USA. Macmillan, 1987: 153-163.

14 Caparros-Lefebvre D, Blond S, Pecheux N, Pasquier F Petit $\mathrm{H}$. Evaluation neuropsychologique avant et après Petit $\mathrm{H}$. Evaluation neuropsychologique avant et apres (Paris) 1992; 148(2);117-22.

15 Narabayashi H. Lessons from Stereotaxic Surgery Using Microelectrode Techniques in Understanding Parkinsonism. The Mount Sinai f Med 1988;1:50-57.

16 Schaltenbrand $G, W$ ahren $W$. Atlas for stereotaxy of the human brain, 2nd ed. Stuttgart: G Thieme, 1977.

17 Tasker RR, Organ LW, Hawrylyshyn PA. In: Wilkins RH eds. The thalamus and midbrain of man: a physiological atlas using electrical stimulation. Springfield, Ill; CT Thomas 1982 .

18 Siegfried J. Die Parkinsonsche Krankheit und ihre Behandlung. In: Siegfried J. ed. Wien: Springer Verlag, 1968.

19 Cooper IS. Neurosurgical treatment of the dyskinesias. Clin Neurosurg 1977;24:367-90.

20 Hugues RC, Polgar JG, Weightman D, Walton JN. LDopa in parkinsonism and the influence of previous Dopa in parkinsonism and the

21 Duvoisin RC. Hyperkinetic reactions with L-DOPA. In: Yahr MD, ed. Current concepts in the treatment of Parkinsonism, Vol 1. New York: Raven Press. 1974;1: 203-10.

22 Narabayashi H, Yokoshi F, Nakajima Y. LevodopaNeurosurg Psychiatry 1984;47:831-9.
23 Albin RL, Young AB, Penney JB. The functional anatomy of basal ganglia disorders. Trends in Neurolog Sci 1989; 12:366-75.

24 Boyce S, Clarke E, Uquin R, Peggs D, Robertson RG, Mitchell IJ, Sambrook MA, Crossman AR. Induction of chorea and dystonia in Parkinsonian primates. Movement Disorders 1990;5:3-7.

25 Crossman AR. A hypothesis on the pathophysiological mechanisms that underlie levodopa or dopamine agonist-induced dyskinesia in Parkinson's disease: implications for the future strategies in treatment. Movement Disorders 1990;5:100-108.

26 Crossman AR, Mitchell IJ, Sambrook MA, Jackson A. Chorea and Myoclonus in the Monkey induced by gamma-aminobutyric acid antagonism in the lentiform complex. The site of drug action and a hypothesis for complex. The site of drug action and a hypothesis for the neural

27 Mitchell IJ, Cross AJ, Sambrook MA, Crossman AR. Neural mechanisms mediating 1-methyl-4-phenyl1,2,3,6-tetrahydropyridine-induced parkinsonism in the
monkey: relative contributions of the striatopallidal and striatonigral pathways as suggested by 2-deoxyglucose uptake. Neurosci Lett 1986;63:61-65.

28 Crossman AR, Sambrook MA, Mitchell IJ, Jackson A, Clarcke CE, Robertson RG, Boyce S. Basal ganglia mechanisms mediating experimental dyskinesia in the monkey. In: Carpenter MB, Jayaraman, eds. The basal ganglia II: structure and function-current concepts. Advances in Behavioral Biology, vol 32. New York: Plenum Press, 1987:377-94.

29 Graybiel A, Ragsdale CW. Fiber connections of the basal ganglia. Progress in Brain Research 1979;51:237-65.

30 Alexander GE, De Long MR, Strick PL. Parallel organization of functionally segregated circuits linking basal zation of functionally segregated circuits linking basal

31 Agid $\mathrm{Y}$ Bonnet AM, Ruberg M, Javoy-Agid F. Pathophysiology of L-Dopa-Induced Abnormal Involuntary movements. In: Casey $D$, Chase $T N$, Christensen V, Gerlach J, eds. Dyskinesia-SpringerVerlag, research and treatment (Psychopharmacology Supplementum 2). Berlin-Heidelberg: 1985:145-59. 